Review began 11/10/2021 Review ended 11/14/2021 Published 11/16/2021

๑) Copyright 2021

Basma et al. This is an open access article distributed under the terms of the Creative Commons Attribution License CC-BY 4.0. which permits unrestricted use, distribution, and reproduction in any medium, provided the original author and source are credited.

\section{Simplifying the Surgical Classification and Approach to the Posterolateral Skull Base and Jugular Foramen Using Anatomical Triangles}

\author{
Jaafar Basma 1, 2 , Kara A. Parikh ${ }^{3}$, Nickalus R. Khan 4, 1 , L. Madison Michael II 4, 1 , Jeffrey M. Sorenson 4, \\ , Jon H. Robertson ${ }^{4,1}$ \\ 1. Neurological Surgery, The University of Tennessee Health Science Center, Memphis, USA 2. Laboratory, Medical \\ Education Research Institute, Memphis, USA 3. Neurosurgery, The University of Tennessee Health Science Center, \\ Memphis, USA 4. Neurological Surgery, Semmes-Murphey Clinic, Memphis, USA
}

Corresponding author: Jaafar Basma, jaafarbasma@hotmail.com

\section{Abstract \\ Introduction}

Lesions of the jugular foramen (JF) and postero-lateral skull base are difficult to expose and exhibit complex neurovascular relationships. Given their rarity and the increasing use of radiosurgery, neurosurgeons are becoming less experienced with their surgical management. Anatomical factors are crucial in designing the approach to achieve a maximal safe resection.

\section{Methods and methods}

Six cadaveric heads (12 sides) were dissected via combined post-auricular infralabyrinthine and distal transcervical approach with additional anterior transstyloid and posterior far lateral exposures. Contiguous surgical triangles were measured, and contents were analyzed. Thirty-one patients (32 lesions) were treated surgically between 2000 and 2016 through different variations of the retro-auricular distal cervical transtemporal approaches.

\section{Results}

We anatomically reviewed the carotid, stylodigastric, jugular, condylar, suboccipital, deep condylar, mastoid, suprajugular, suprahypoglossal (infrajugular), and infrahypoglossal triangles. Tumors included glomus jugulare, lower cranial nerve schwannomas or neurofibromas, meningiomas, chondrosarcoma, adenocystic carcinoma, plasmacytoma of the occipitocervical joint, and a sarcoid lesion. We classified tumors into extracranial, intradural, intraosseous, and dumbbell-shaped, and analyzed the approach selection for each.

\section{Conclusion}

Jugular foramen and posterolateral skull base lesions can be safely resected through a retro-auricular distal cervical lateral skull base approach, which is customizable to anatomical location and tumor extension by tailoring the involved osteo-muscular triangles.

Categories: Neurosurgery, Anatomy

Keywords: meningioma, glomus jugulare, hypoglossal schwannoma, distal cervical approach, hypoglossal canal, styloid process, infralabyrinthine approach, far lateral, jugular foramen

\section{Introduction}

Surgical access to distal cervical and jugular foramen (JF) lesions is difficult given the anatomical complexity of the region, technical challenges, and risk of neurovascular injuries. Approach selection is key in devising the surgical strategy and achieving complete resection. Given the usual depth of the pathology, muscular and bony structures should be unlocked in a stepwise and targeted fashion. Tailoring the approach to the individual case allows for adequate exposure around the lesion while minimizing unnecessary steps, wasted time, and risk of collateral injuries.

Tumor extension has been classified based on pathological diagnosis and its anatomical extension (glomus tumors, cranial nerve schwannomas, meningiomas) [1-7]. Several classification schemes have also been proposed to help plan the surgical approach. Dr. Albert Rhoton Jr. classified the JF approaches into an anterior group through the tympanic bone (preauricular subtemporal-infratemporal fossa approach), a lateral group through the mastoid bone (post-auricular transtemporal infralabyrinthine approach, and other transmastoid approaches), and a posterior group (retrosigmoid, far lateral and trans-condylar approaches) [8]. The senior author (JHR) traditionally adopted the lateral distal cervical retro-auricular transtemporal (LDC-RATT) approach because it offers direct access to the JF, is versatile, and can be tailored to individual lesions $[9,10]$. We recently deconstructed this approach into anatomical triangles and analyzed its different 


\section{Cureus}

angles of exposure [11].

In this paper, we review a clinical series of 32 lesions where a modification of the LDC-RATT was used by the senior author (JHR) for surgical resection of distal cervical and posterolateral skull base lesions, either extending to or in close proximity to the jugular foramen. We classified these according to their anatomical extension and analyzed the anatomical factors influencing approach selection and modification. Such a classification was combined with an illustration of the jugular foramen triangles in planning and executing the approach.

\section{Materials And Methods}

\section{Anatomical dissections}

Six preserved cadaveric heads (12 sides) were dissected at the Medical Education and Research Institute (MERI) microsurgical laboratory in Memphis, TN. The heads had no known intracranial or cervical pathology and were fixed and injected with colored silicone rubber. All cadaver specimens had preserved distal necks proximally, at least to the level of the omohyoid muscle.

Two types of retro-auricular curvilinear C-shaped skin incisions were made posterior to the pinna: either 3 $\mathrm{cm}$ posterior to the pinna for a standard lateral approach, or further medially close to the midline in order to expose the occipital condyle (modified approach with a far lateral component; Figure 1). Three major landmarks were constantly recognized: the mastoid tip, styloid process, and transverse process of the atlas (TP-C1). The following superficial triangles were defined and identified as previously described (Figures 2 and 3): (i) mastoid triangle, between the asterion, mastoid tip, and the supra-meatal crest (Figure 2A) [12]; (ii) carotid triangle, limited by the omohyoid, the sternocleidomastoid (SCM), and the digastric muscles (Figure 2B) [13]; and (iii) stylodigastric triangle between the digastric and the stylo-hyoid muscles (Figure 2C) [12]

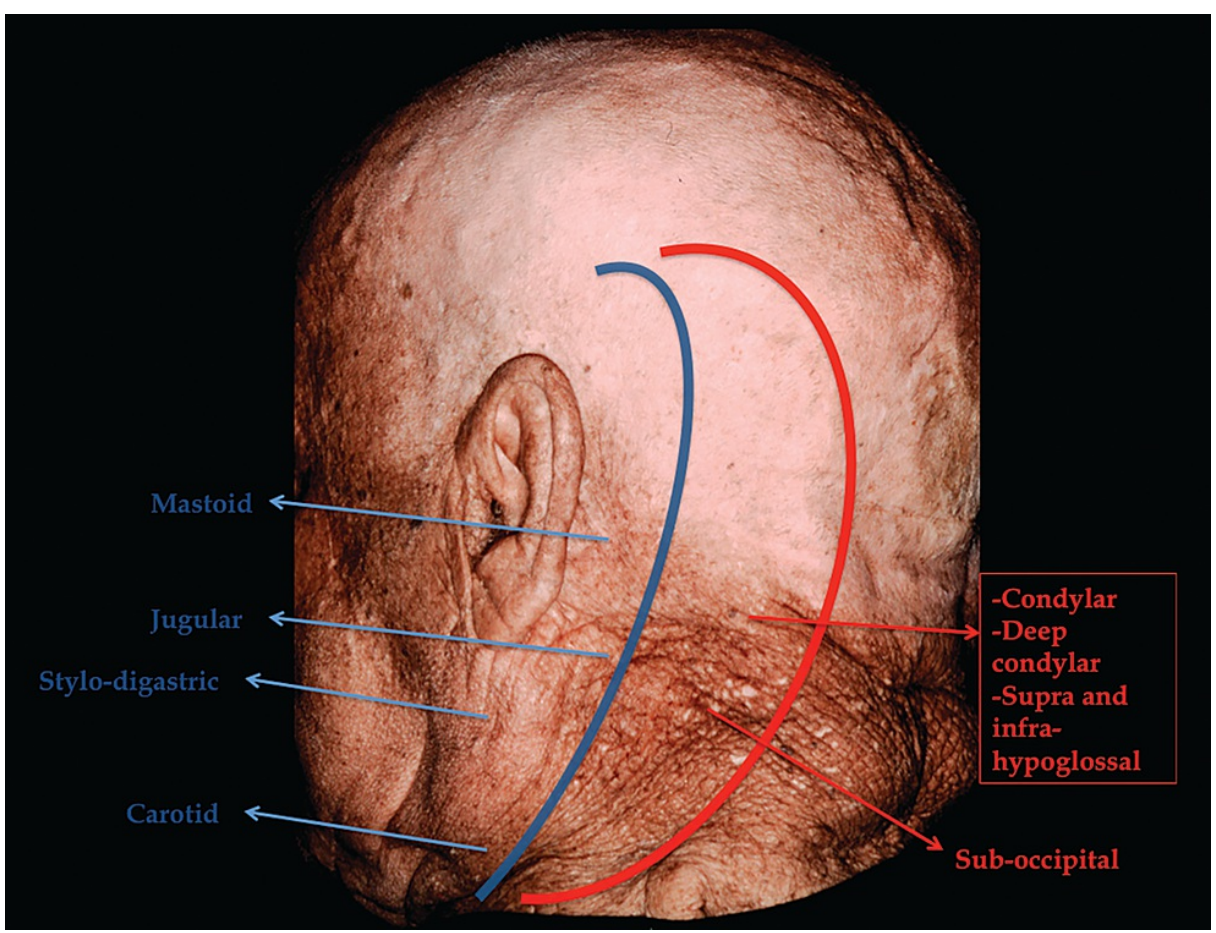

FIGURE 1: Planning the lateral distal cervical retro-auricular transtemporal approach in relation to anatomical triangles.

To expose the jugular foramen (blue), the approach unlocks the carotid, stylo-digastric, jugular, and mastoid triangles. A modified postero-lateral approach (red) extends the exposure medially to the condylar region, leading to the condylar, deep condylar, suboccipital, supra-hypoglossal, and infra-hypoglossal triangles. 


\section{Cureus}
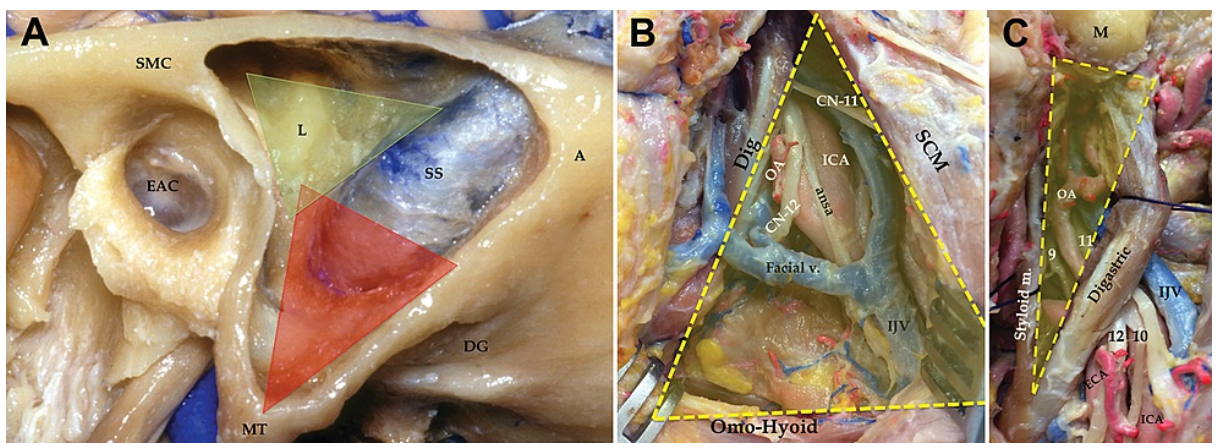

FIGURE 2: Mastoid, carotid, and stylodigastric triangles.

(A) Mastoid triangle: drilled between the supra-mastoid crest (SMC), asterion (label A), and mastoid tip (MT). It can be divided into an infra-labyrinthine or supra-jugular sector (red), and a pre-sigmoid sector (yellow). Labels: A asterion; SMC: supra-mastoid crest; DG: digastric groove; EAC: external auditory canal; L: labyrinth; MT: mastoid tip; SS: sigmoid sinus. (B) Carotid triangle: limited by the sternocleidomastoid (SCM), digastric (Dig), and omohyoid muscles. Labels: ansa: ansa cervicalis; $\mathrm{CN}-11$ : accessory nerve; $\mathrm{CN}-12$ : hypoglossal nerve; Dig: digastric muscle; ICA: internal carotid artery; IJV: internal jugular vein; OA: occipital artery; SCM: sternocleidomastoid. (C) Stylodigastric triangle: defined by the (a) digastric muscle, (b) styloid muscles, and an imaginary line between the digastric groove and base of the styloid process. Labels: $9=$ glossopharyngeal nerve; $10=$ vagus nerve; $11=$ accessory nerve; $12=$ hypoglossal nerve; ECA: external carotid artery; IJV: internal jugular vein; M: mastoid process
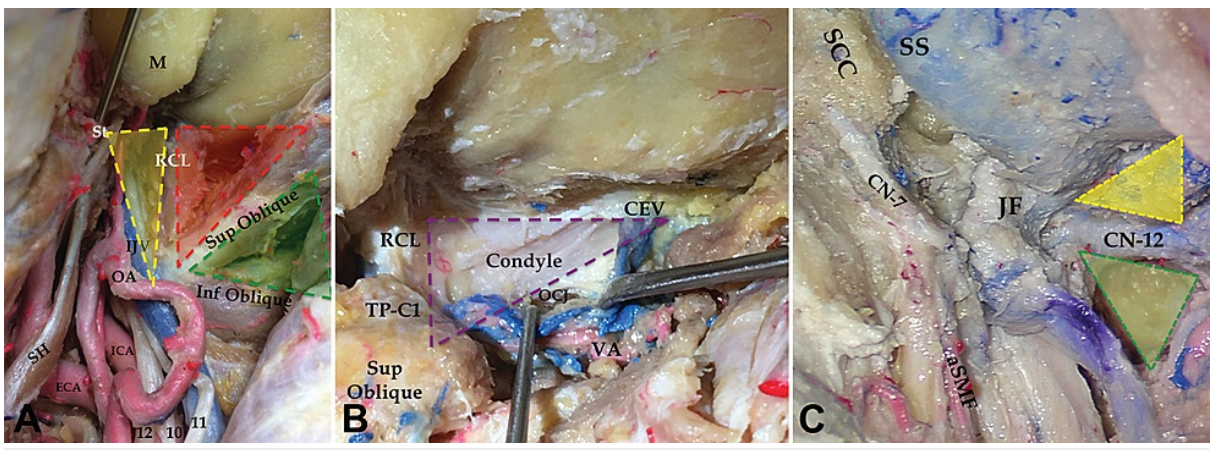

FIGURE 3: Suboccipital, condylar, jugular, supra-hypoglossal, and infrahypoglossal triangles.

(A) Suboccipital triangle (green): limited by the superior and inferior obliques muscles. Condylar triangle (red): between the superior oblique and the rectus capitis lateralis $(R C L)$ muscles. Jugular triangle (yellow): limited by the RCL, transverse process of the atlas, and the base of the styloid (St). (B) Deep condylar and trans-condylar triangles: defined between the condylar emissary vein (CEV), RCL, and transverse process of the atlas (TP-C1). The atlanto-occipital joint (or occipitocervical joint, OCJ) is seen after mobilizing and retracting the vertebral artery (VA) inferiorly. (C) Supra-hypoglossal (yellow) and infra-hypoglossal (green) triangles: delineated after drilling the occipital condyle with the former leading to the infrajugular area, and the latter to the occipitocervical joint. Labels: aSMF: artery of stylomastoid foramen; $\mathrm{CN}-7$ : facial nerve; $\mathrm{CN}-12$ : hypoglossal nerve; JF: jugular foramen.

Detaching the digastric muscle and mobilizing it inferiorly exposed the TP-C1 and the surrounding deep muscular triangles: (iv) suboccipital triangle between the superior and inferior oblique muscles (Figure $3 \mathrm{~A}$ ) [14], and (v) condylar triangle between the superior oblique and rectus capitis lateralis muscles (Figure 3A) [15]. We also previously defined the (vi) "jugular triangle" between rectus capitis lateralis, TP-C1, and the base of the styloid process, as the lateral limit to the jugular foramen (Figure 3A) [11]. We proposed the (vii) "deep condylar triangle" between the condylar emissary vein, the jugular process of the occipital bone (site of insertion of rectus capitis lateralis), and the transverse process of the atlas (Figure 3B) [11]. This helped us delineate exactly where the occipital condyle is located from a lateral perspective. Drilling the occipital condyle led us to the hypoglossal canal. Above it, the (viii) supra-hypoglossal triangle was defined between the hypoglossal dura inferiorly, foramen magnum dura medially, and jugular bulb laterally. Below it, the (9) infra-hypoglossal triangle was identified between the hypoglossal dura, atlanto-occipital joint, and jugular foramen (Figure 3C) [16].

\section{Case series}

We retrospectively reviewed illustrative cases in which different modifications of the LDC-RATT approach were used by the senior author (JHR) at our institution between 2000 and 2016. Emphasis was placed on 


\section{Cureus}

challenging lesions, such as glomus jugulare tumors, lower cranial nerve schwannomas, jugular foramen meningiomas, and occipital condyle and/or atlanto-occipital joint lesions extending to the jugular foramen.

Pre-operative imaging (including computed tomography [CT] scans, magnetic resonance imaging [MRI], and, if available, four-vessel angiography) and intraoperative findings were reviewed on 31 patients treated surgically for 32 such lesions. We focused on the anatomical factors of these lesions, which were deemed crucial in planning the surgical approach. We obtained Institutional Review Board approval from The University of Tennessee Health Science Center (UTHSC) (No. 20-07874-XP). Informed consent was waived because of the retrospective nature of the data.

Anatomically, lesions were classified according to their origin and extension (Table 1). Extracranial tumors (type 1) are limited to the distal cervical region. While type 1A lesions are located below the digastric muscle in the carotid triangle (Figures $2 B$ and 4 ), type $1 \mathrm{~B}$ tumors are in the stylodigastric triangle close to the skull base (Figures $2 \mathrm{C}$ and 5). Type 2 tumors are intracranial and involve at least the cerebello-medullary and/or the cerebello-pontine cisterns (Figure 6). Type 3 tumors are typically located at the level of the skull base and are termed intra-osseous or intraforaminal. Type 3A is limited to the jugular foramen (Figure 7), while type $3 \mathrm{~B}$ lesions extend to the petrous bone and/or the internal auditory meatus, and type $3 \mathrm{C}$ tumors to the occipital condyle region (Figure $8 A-8 B$ ). Type 4 tumors are dumbbell-shaped, with $4 \mathrm{~A}$ involving the jugular foramen and $4 \mathrm{~B}$ the medial aspect of the jugular foramen and hypoglossal canal (Figure $9 A-9 B$ ). Type 4 tumors can be true or triple dumbbell-shaped (4t) involving the extracranial, foraminal, and intracranial compartments (Figures 5A-5B and 9A-9B); predominantly foraminal and extra-cranial (4e); or foraminal and intracranial (4i).

\section{Group 1: Extracranial}

1A Carotid triangle

1B Stylodigastric triangle

Group 2: Intracranial Intradural

Group 3: Intraosseous or Intraforaminal

$3 \mathrm{~A}$ Jugular foramen

3B Petrous/IAC

3C Hypoglossal canal/OC

Group 4: Dumbbell-shaped

4A Jugular foramen

4Ae Predominant extracranial

4Ai Predominant intracranial

4At True dumbbell-shaped

4B Hypoglossal canal/OC

4Be Predominant extracranial

4Bi Predominant intracranial

4Bt True dumbbell-shaped

\section{TABLE 1: Classification of posterolateral skull base/jugular foramen lesions depending on their} anatomical extension.

IAC: internal auditory meatus; OC: occipital condyle. 


\section{Cureus}
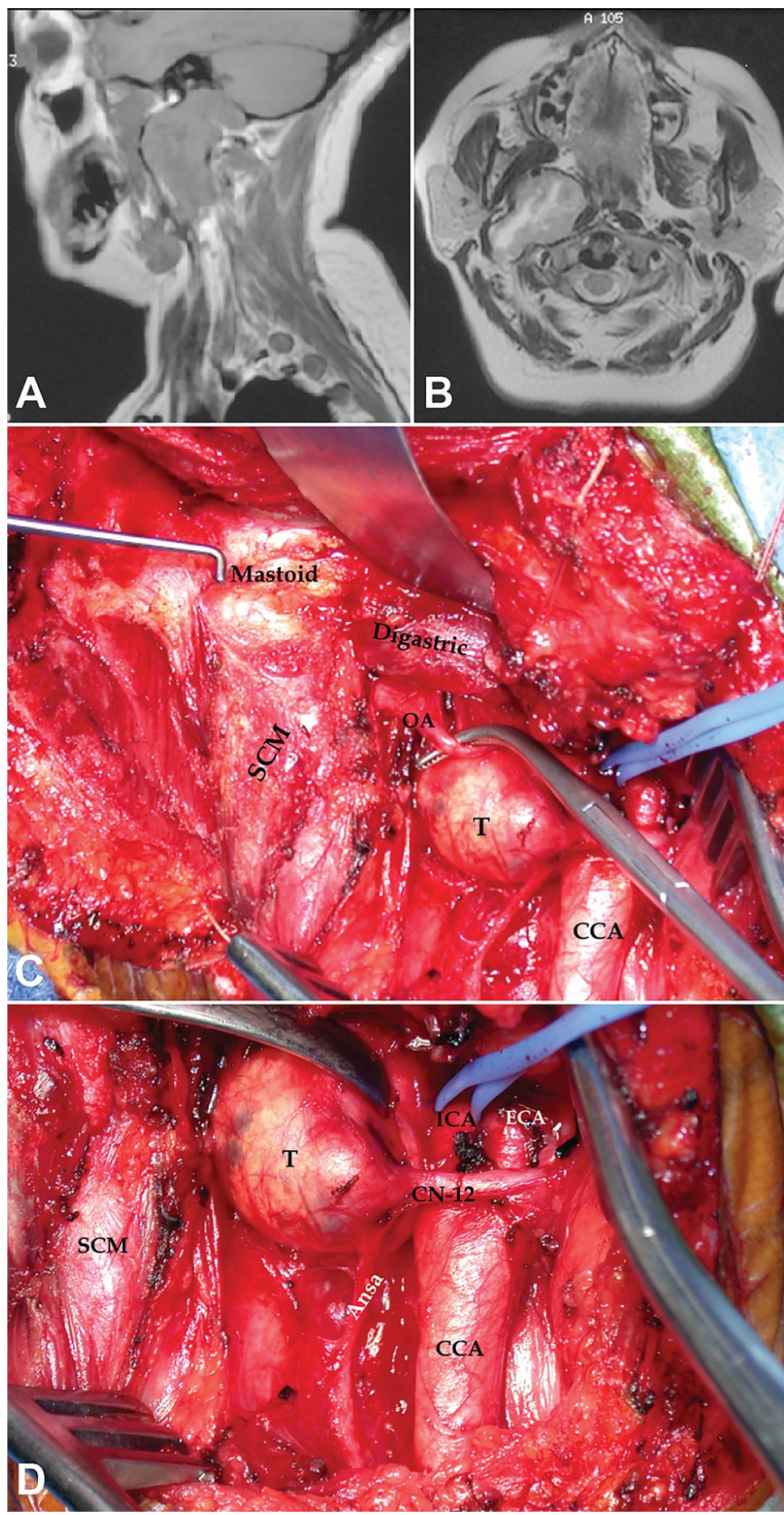

FIGURE 4: Dumbbell-shaped hypoglossal schwannoma accessed via carotid triangle.

T1 sagittal (A) and T2 axial (B) MRI scan of a right-sided triple dumbbell-shaped hypoglossal schwannoma in a patient in their early 40s who presented with headaches, nausea, vomiting, and right tongue atrophy (case 31).

The patient underwent a combined approach with antero-lateral neck dissection, exposing a tumor in the carotid triangle (C, D), followed by a retrosigmoid craniotomy. Labels: ansa: ansa cervicalis; CCA: common carotid artery; $\mathrm{CN}$-12: hypoglossal nerve; ECA: external carotid artery; ICA: internal carotid artery; OA: occipital artery; T: tumor. 


\section{Cureus}



FIGURE 5: Glossopharyngeal schwannoma accessed via stylodigastric triangle.

Axial T2 (A) and coronal T1 (B) gadolinium-enhanced MRI of a glossopharyngeal schwannoma in a pediatric patient with neurofibromatosis type-1 presenting with a neck mass (case 4). Note the tumor's location is distal in the neck and medial to the internal carotid artery. A distal lateral cervical exposure was performed $(C, D)$ and the stylodigastric triangle opened by mobilizing the digastric muscle. Labels: $\mathrm{CN}-12$ : hypoglossal nerve; IJV: internal jugular vein; OA: occipital artery; SCM: sternocleidomastoid muscle; T: tumor. 


\section{Cureus}

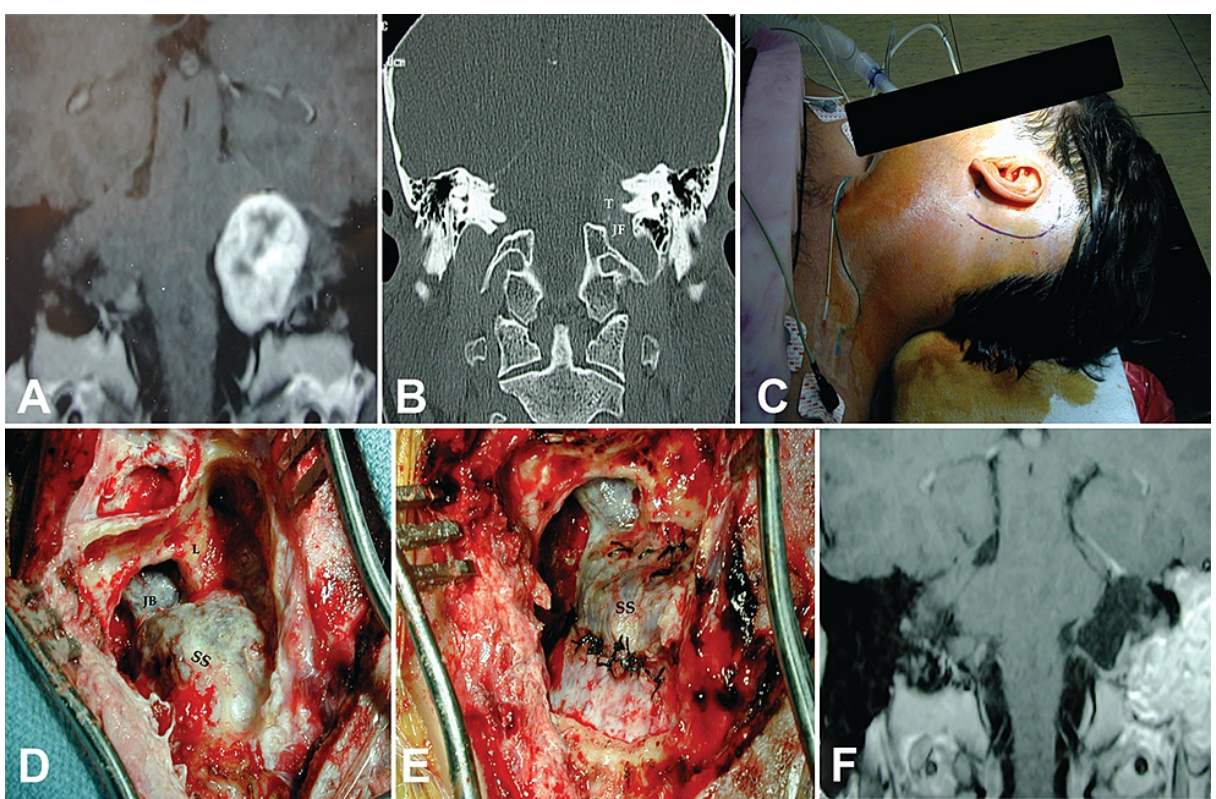

FIGURE 6: Glossopharyngeal schwannoma accessed via mastoid triangle.

Coronal T1 gadolinium-enhanced (A) and computed tomographic scan (B) of a mostly intradural glossopharyngeal schwannoma (case 8). The patient in their late 30 s presented with hearing loss, tinnitus, and vertigo, and the tumor was mostly intracranial impinging toward the jugular foramen (type 2). A retroauricular incision was planned $(C)$ and the mastoid triangle was exposed in both its presigmoid and suprajugular sectors (D). A combined presigmoid and retrosigmoid intradural approach was performed $(E)$ to achieve a gross total resection, as seen on the postoperative coronal MRI scan (F). Labels: JB: jugular bulb; L: labyrinth; SS: sigmoid sinus.
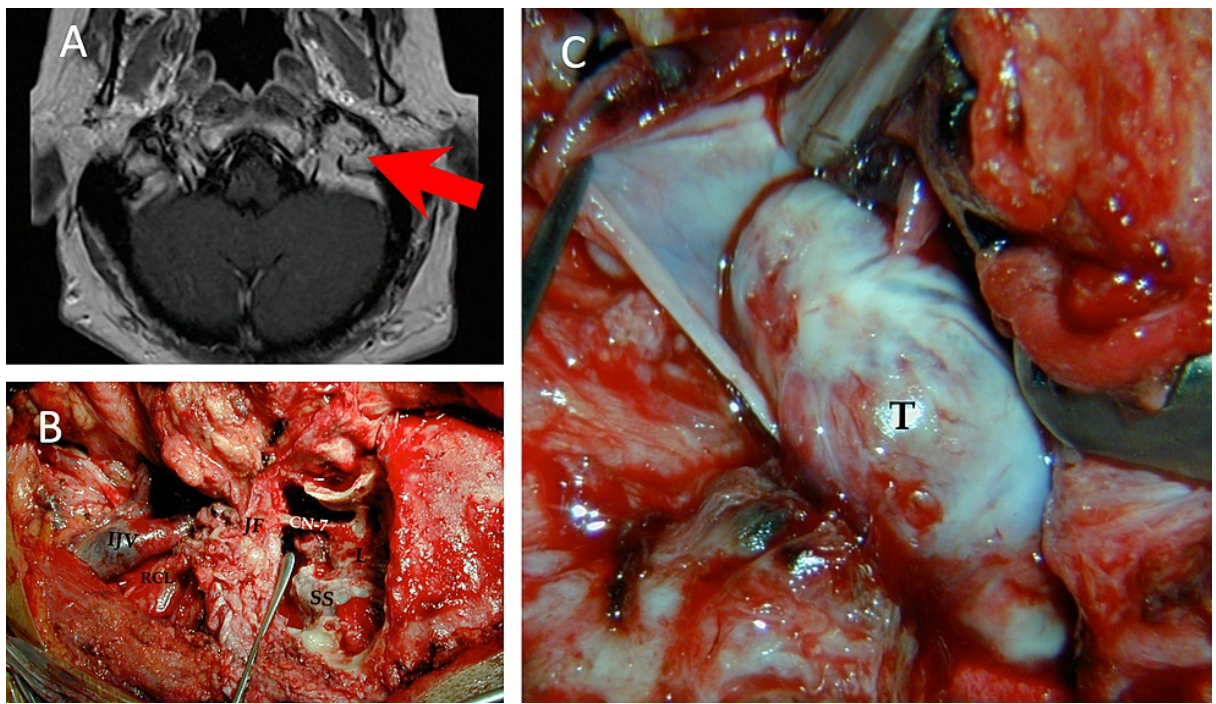

FIGURE 7: Glomus jugulare tumor accessed via jugular triangle.

Exposure of the deeper surgical triangles, including the jugular triangle. (A) Axial T1 MRI scan demonstrating a left glomus jugulare tumor in a patient in their mid-40s presenting with hearing loss and pulsatile tinnitus (case 9). A lateral distal cervical retro-auricular transtemporal (infra-labyrinthine) approach was performed to expose the jugular foramen (JF) (B). The fallopian canal was skeletonized keeping a bone shell around the facial nerve (CN7) to preserve it. After ligating the sigmoid sinus and the jugular vein, the vein was opened, and the tumor resected from within $(C)$. The medial wall of the vein was preserved to protect the neighboring lower cranial nerves. Labels: CN-7: facial nerve; IJV: internal jugular vein; JF: jugular foramen; L: labyrinth; RCL: rectus capitis lateralis; SS: sigmoid sinus. 


\section{Cureus}
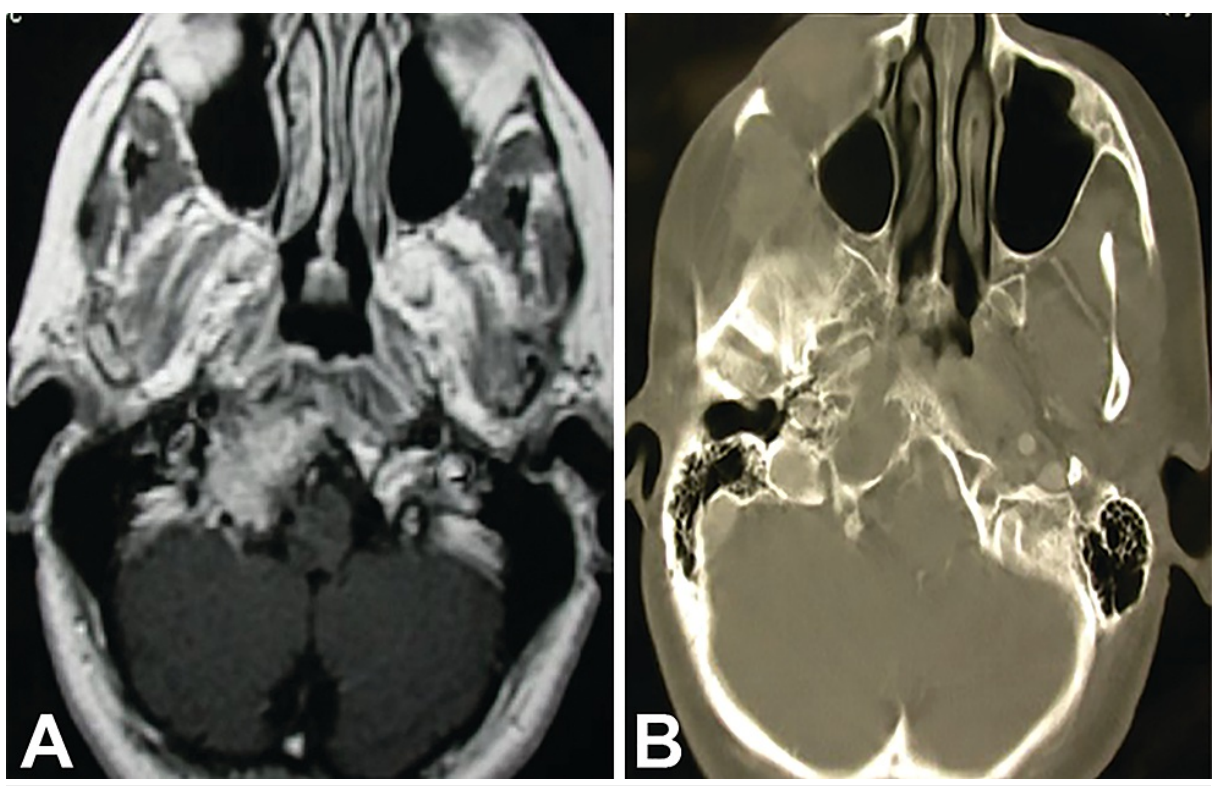

FIGURE 8: Plasmacytoma accessed via infra-hypoglossal triangle.

(A) A contrasted T1 axial MRI and (B) axial CT scan demonstrating a lesion in the right occipitocervical joint. The patient complained of severe right-sided neck pain, and a modified approach was done exposing the lesion in the infra-hypoglossal triangle. Pathology was consistent with plasmacytoma (case 16).

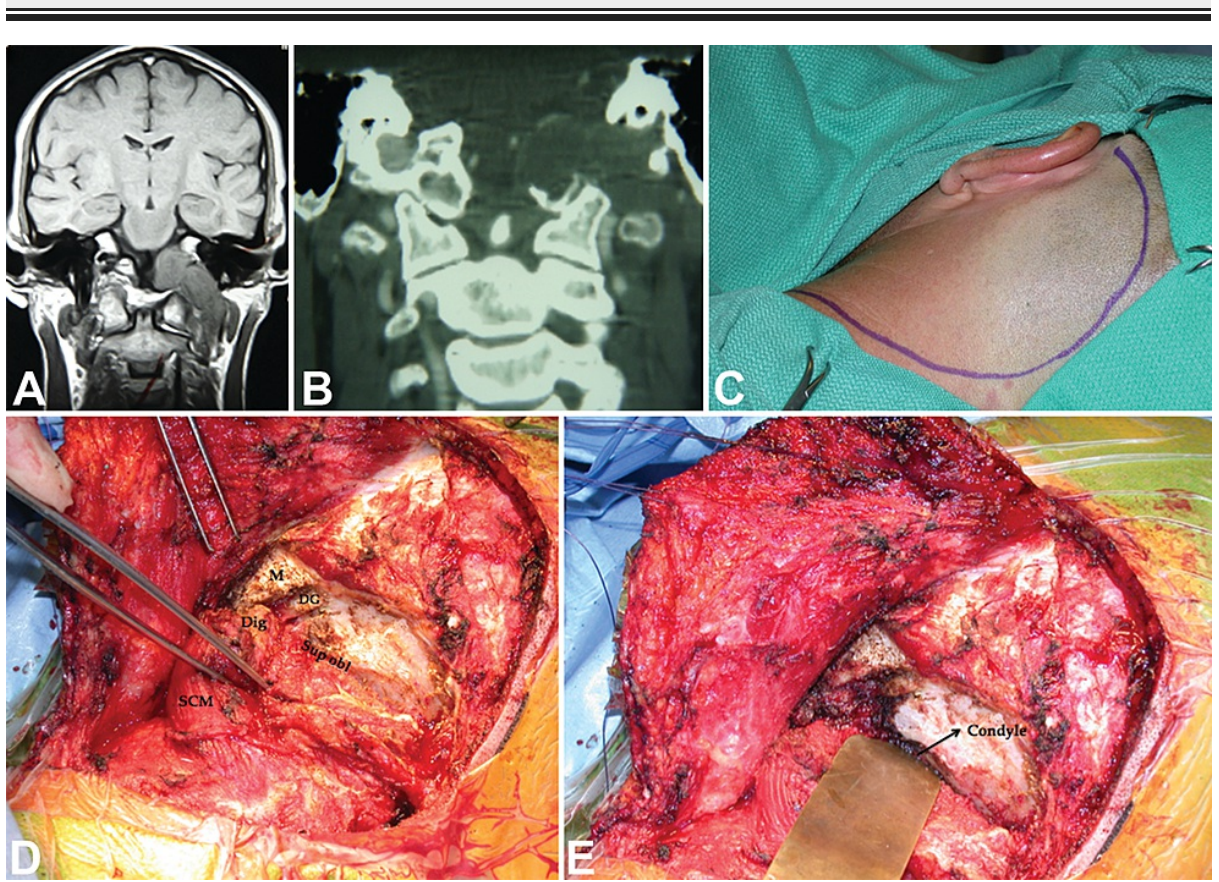

FIGURE 9: Hypoglossal schwannoma accessed via condylar triangle.

Coronal T1 MRI (A) and coronal CT (B) scans showing a left hypoglossal schwannoma involving the cerbellomedullary cistern, occipital condyle, and hypoglossal canal, medial jugular foramen, and the distal cervical region. The 37-year-old man presented with headache, left neck pain, and hemiatrophy of the left tongue (case 32). A modified approach that combined a far lateral exposure was done $(C, D, E)$ to identify the condylar triangle under the superior oblique muscle (sup obl). The intracranial, intraforaminal, and cervical components of the tumor were then completely resected. Labels: DG: digastric groove; Dig: digastric muscle; M: mastoid; SCM: sternocleidomastoid, Sup obl: superior oblique muscle.

We then analyzed the different modifications of the LDC-RATT approach as employed in clinical practice by the senior author (JHR), compared to our anatomical dissections and of the described surgical triangles.

\section{Results}




\section{Cureus}

\section{Anatomical dissections}

Contents of the different triangles along with their respective measurements have been previously reported [11]. Table 2 summarizes the triangles as they relate to the modifications of the LDC-RATT approach, including the different possible surgical steps and exposure advantages related to the jugular foramen region.

\begin{tabular}{|c|c|c|}
\hline Triangle & Major surgical steps & Exposure to JF region \\
\hline 1. Carotid & $\begin{array}{l}\text { Medial SCM approach and carotid sheath } \\
\text { dissection }\end{array}$ & Proximal control, distal course of LCN'S \\
\hline \multirow{2}{*}{ 2. Stylodigastric } & Mobilizing/detaching digastric muscle & Lateral JF and distal cervical region, distal ICA \\
\hline & Removing styloid process & Anterior JF, distal ICA \\
\hline \multirow[b]{2}{*}{ 3. Mastoid } & Infralabyrinthine & Lateral and superior JF \\
\hline & Retrolabyrinthine, translabyrinthine, transcochlear & $\begin{array}{l}\text { Superior JF and JB, IAC and petrous bone, intradural } \\
\text { exposure }\end{array}$ \\
\hline \multirow{2}{*}{ 4. Jugular } & $\mathrm{RCL}$ and jugular process & Posterior JF \\
\hline & Cutting the jugular ring & Medial JF \\
\hline 5. Condylar & Detaching superior oblique muscle & Expose the OC \\
\hline 6. Suboccipital & Detach the superior and inferior oblique & Expose VA \\
\hline 7. Deep condylar & Drill the OC & Medial JF, HC \\
\hline $\begin{array}{l}\text { 8. Supra- } \\
\text { hypoglossal }\end{array}$ & Drill the jugular tubercle & Inferior JF Premedullary cistern \\
\hline 9. Infrahypoglossal & Drill below the hypoglossal canal & Expose the atlanto-occipital joint \\
\hline
\end{tabular}

\section{TABLE 2: Surgical triangles deconstructing the lateral distal cervical retro-auricular transtemporal approach, and the potential steps involved in each.}

EAC: external auditory meatus; HC: hypoglossal canal; IAC: internal auditory meatus; ICA: internal carotid artery; IJV: internal jugular vein; JB: jugular bulb; JF: jugular foramen; LCN: lower cranial nerves (CN9-12); OC: occipital condyle; RCL: rectus capitis lateralis; SCM: sternocleidomastoid muscle; VA: vertebral artery.

A standard LDC-RATT combines a distal medial sternocleidomastoid approach with a retro-auricular transmastoid approach. The incision is usually started behind the pinna and continued inferiorly over a neck crease on the medial aspect of the SCM. The distal cervical component of the approach is divided into a carotid triangle (harboring the proximal cervical internal carotid artery [ICA], external carotid artery [ECA], and common carotid artery [CCA]; internal jugular vein [IJV]; ansa cervicalis, and lower cranial nerves [CN] $\mathrm{X}$-XII) and a stylodigastric triangle (containing the distal ICA, distal IVJ, distal ECA, and its branches, and CN IX-XII), separated by the digastric muscle. Extracranial schwannomas or distal IJV/ICA lesions can be accessed through these triangles (Figures $2 B, 2 C, 4$, and 5).

Both the digastric and SCM muscles attach to the mastoid bone and should be reflected if further steps of the approach are necessary. Drilling the mastoid bone can be compartmentalized into an infralabyrinthine space (or "suprajugular space" to expose the superior aspect of the jugular foramen and jugular bulb), and a retrolabyrinthine/translabyrinthine space (leading to the presigmoid dura; Figures $2 \mathrm{~A}$ and 6). The IJV enters the JF in the jugular triangle (TPC1-rectus capitis lateralis-base of the styloid process). Thus, exposing a standard glomus jugulare tumor requires opening the carotid, stylodigastric, mastoid, and jugular triangles (Figures $3 \mathrm{~A}$ and 7). Palpating the transverse process of the atlas, the styloid process, and the mastoid tip is helpful in orienting the surgeon toward the correct triangles.

A modified LDC-RATT is helpful for lesions involving the region of the occipital condyle and medial aspect of the jugular foramen. This approach adds a far lateral exposure and is devised by curving the retro-auricular incision further medially. It allows the exposure of the occipital bone beyond the occipitomastoid suture and the suboccipital triangle beneath it. Again, the transverse process of the atlas represents a key anatomical structure that helps delineate the suboccipital triangle (where the vertebral artery is identified), and the condylar triangle (harboring the occipital condyle $[\mathrm{OC}]$ ). The $\mathrm{OC}$ is delineated exactly in the deep condylar triangle, and drilling it exposes the hypoglossal canal. The supra-hypoglossal triangle aids in exposing the 
inferior aspect of the jugular foramen (described in the literature as the infrajugular approach), while the infra-hypoglossal triangle leads to the atlanto-occipital joint (Figures 3B, 3C, and 8).

\section{Case series}

The confirmed pathological diagnosis of the reviewed lesions included: 13 lower cranial nerve schwannomas or neurofibromas (eight hypoglossal, two vagal, two glossopharyngeal, and one accessory), seven glomus jugulare/vagale tumors, seven meningiomas (mostly petrous or petroclival extending into the jugular foramen), one chondrosarcoma, one adenocystic carcinoma, one plasmacytoma of the occipitocervical joint, one eagle syndrome (hypertrophied styloid process compressing the internal carotid artery and causing transient ischemic attack [TIA] like syndrome), and one sarcoid lesion in the occipital condyle/medial jugular foramen area. Table 3 summarizes the clinical presentation, pathology, employed surgical approach, and extent of resection in each of these cases.

\begin{tabular}{|c|c|c|c|c|c|c|c|}
\hline Case & Presentation & Pathology & Location & Type & Approach & Triangles & EOR \\
\hline 1 & Neck mass/pain & CN12 schwannoma & Lateral cervical & $1 \mathrm{~A}$ & Lateral cervical & Carotid & GTR \\
\hline 2 & Tongue atrophy & CN12 schwannoma & Lateral cervical & $1 \mathrm{~A}$ & Lateral cervical & Carotid & GTR \\
\hline 3 & $\begin{array}{l}\text { Hoarseness, tongue } \\
\text { atrophy }\end{array}$ & CN10 schwannoma & Distal cervical & 1B & Distal cervical & Carotid, SD & GIR \\
\hline 4 & NF1, neck mass & CN9 schwannoma & Distal cervical & 1B & Distal cervical & Carotid, SD & GTR \\
\hline 5 & NF1, neck mass & CN10 neurofibroma & Distal cervical & 1B & Distal cervical & Carotid, SD & GTR \\
\hline 6 & I rapezlus weakness/pain & CN 11 schwannoma & Distal cervical & 1B & Distal cervical & Carotid, SD & GTR \\
\hline 7 & Transient ischemic attacks & $\begin{array}{l}\text { Hypertrophic styloid process } \\
\text { (Eagle syndrome) }\end{array}$ & Distal cervical & 1B & Distal cervical & Carotid, SD & GTR \\
\hline 8 & $\begin{array}{l}\text { Hearing loss, tinnitus, } \\
\text { vertigo }\end{array}$ & CN9 schwannoma & CPA and CMC & 2 & $\begin{array}{l}\text { Combined presigmoid and } \\
\text { retrosigmoid }\end{array}$ & Mastoid & GTR \\
\hline 9 & Hearing loss, tinnitus & Glomus jugulare & $\mathrm{JF}$ & $3 A$ & LDC-RATT & $\begin{array}{l}\text { Carotid, SD, } \\
\text { mastoid, jugular }\end{array}$ & GTR \\
\hline 10 & Headaches, tinnitus & Glomus jugulare & $\mathrm{JF}$ & $3 A$ & LDC-RATT & $\begin{array}{l}\text { Carotid, SD, } \\
\text { mastoid, jugular }\end{array}$ & GTR \\
\hline 11 & Headaches, tinnitus & Glomus jugulare & $\mathrm{JF}$ & $3 A$ & LDC-RATT & $\begin{array}{l}\text { Carotid, SD, } \\
\text { mastoid, jugular }\end{array}$ & GTR \\
\hline 12 & $\begin{array}{l}\text { Severe headaches/ neck } \\
\text { pain }\end{array}$ & Sarcoid & $\mathrm{JF}$ & $3 \mathrm{~A}$ & LDC-RATT & $\begin{array}{l}\text { Carotid, SD, } \\
\text { mastoid, jugular }\end{array}$ & GTR \\
\hline 13 & $\begin{array}{l}\text { Hearing loss, headaches, } \\
\text { tinnitus }\end{array}$ & Glomus jugulare & JF + petrous bone & 3B & LDC-RATT/translab & $\begin{array}{l}\text { Carotid, SD, } \\
\text { mastoid, jugular }\end{array}$ & NTR \\
\hline 14 & $\begin{array}{l}\text { Hearing loss, facial } \\
\text { weakness, dizziness }\end{array}$ & Glomus jugulare & $\mathrm{JF}+$ petrous bone & 3B & LDC-RATT/translab & $\begin{array}{l}\text { Carotid, SD, } \\
\text { mastoid, jugular }\end{array}$ & NTR \\
\hline 15 & headaches, hearing loss & Chondrosarcoma & $\mathrm{JF}+$ petroclival & 3B & LDC-RATT/translab & $\begin{array}{l}\text { Carotid, SD, } \\
\text { mastoid, jugular }\end{array}$ & NTR \\
\hline 16 & Severe neck pain & plasmacytoma & Condyle, medial JF & $3 \mathrm{C}$ & $\begin{array}{l}\text { Modified LDC-RATT + far } \\
\text { lateral }\end{array}$ & $\begin{array}{l}\text { Condylar, } \\
\text { suboccipital }\end{array}$ & GTR \\
\hline 17 & $\begin{array}{l}\text { Pulsating neck mass, } \\
\text { CN9-12 palsies }\end{array}$ & Glomus vagale & JF+distal cervical & $4 \mathrm{Ae}$ & Distal cervical + GKS & Carotid, SD & STR \\
\hline 18 & CN10-11 palsies & CN10 schwannoma & $\mathrm{JF}+\mathrm{CPA}$ & $4 \mathrm{Ai}$ & LDC-RATT/translab/presigmoid & $\begin{array}{l}\text { Carotid, SD, } \\
\text { mastoid, jugular }\end{array}$ & NTR \\
\hline 19 & $\begin{array}{l}\text { Ataxia, CN8-12 palsies, } \\
\text { hearing loss }\end{array}$ & $\begin{array}{l}\text { Glomus with aggressive } \\
\text { behavior }\end{array}$ & $\mathrm{JF}+\mathrm{CPA}$ & $4 A \mathrm{~A}$ & $\begin{array}{l}\text { LDC- } \\
\text { RATT/transcochlear/presigmoid }\end{array}$ & $\begin{array}{l}\text { Carotid, SD, } \\
\text { mastoid, jugular }\end{array}$ & STR \\
\hline 20 & Headaches, ataxia & Petrous/JF meningioma & CPA, CMC, JF & $4 \mathrm{Ai}$ & Retrosigmoid & Mastoid, jugular & NTR \\
\hline 21 & $\begin{array}{l}\text { Headaches, ataxia, } \\
\text { hearing loss }\end{array}$ & Petrous/JF meningioma & CPA, CMC, IAC, JF & $4 \mathrm{Ai}$ & Retrosigmoid & Mastoid, jugular & STR \\
\hline
\end{tabular}




\section{Cureus}

\begin{tabular}{|c|c|c|c|c|c|c|c|}
\hline 22 & Headaches, ataxia & Petrous/JF meningioma & $\mathrm{CPA}, \mathrm{CMC}, \mathrm{JF}$ & $4 \mathrm{Ai}$ & Retrosigmoid & Mastoid, jugular & NTR \\
\hline 23 & $\begin{array}{l}\text { Headaches, ataxia, } \\
\text { tinnitus }\end{array}$ & Petrous/JF meningioma & CPA, CMC, JF & $4 \mathrm{Ai}$ & Retrosigmoid & Mastoid, jugular & NTR \\
\hline 24 & $\begin{array}{l}\text { Hearing loss, ataxia, facial } \\
\text { numbness }\end{array}$ & Petroclival/JF meningioma & CPA, CMC, IAC, JF & $4 \mathrm{Ai}$ & Retrosigmoid followed by GKS & Mastoid, jugular & STR \\
\hline 25 & $\begin{array}{l}\text { Hearing loss, ataxia, facial } \\
\text { numbness }\end{array}$ & Petroclival/JF meningioma & CPA, CMC, IAC, JF & $4 \mathrm{Ai}$ & Extended petrosal & Mastoid, jugular & GTR \\
\hline 26 & $\begin{array}{l}\text { Neck mass, CN9-11 } \\
\text { palsies }\end{array}$ & Petrous/ JF meningioma & $\begin{array}{l}\text { CPA/IAC, CMC, JF, distal } \\
\text { cervical }\end{array}$ & 4At & $\begin{array}{l}\text { Stage1: distal cervical; Stage 2: } \\
\text { retrosigmoid }\end{array}$ & $\begin{array}{l}\text { Carotid, SD, } \\
\text { mastoid, jugular }\end{array}$ & STR \\
\hline 27 & $\begin{array}{l}\text { Ataxia, headaches, neck } \\
\text { mass, hearing loss }\end{array}$ & Adenoid cystic carcinoma & $\begin{array}{l}\text { CPA, CMC, JF, distal } \\
\text { cervical }\end{array}$ & 4At & LDC-RATT/translab & $\begin{array}{l}\text { Carotid, SD, } \\
\text { mastoid, jugular }\end{array}$ & NTR \\
\hline 28 & Headaches, CN12 palsy & Hypoglossal schwannoma & $\begin{array}{l}\mathrm{HC} / \text { condyle, medial JF, } \\
\text { distal cervical }\end{array}$ & $4 \mathrm{Be}$ & $\begin{array}{l}\text { Modified LDC-RATT + far } \\
\text { lateral }\end{array}$ & $\begin{array}{l}\text { SD, condylar, } \\
\text { jugular }\end{array}$ & GTR \\
\hline 29 & Headaches, CN12 palsy & Hypoglossal schwannoma & $\begin{array}{l}\mathrm{HC} / \text { condyle, medial JF, } \\
\text { distal cervical }\end{array}$ & $4 \mathrm{Be}$ & $\begin{array}{l}\text { Modified LDC-RATT + far } \\
\text { lateral }\end{array}$ & $\begin{array}{l}\text { SD, condylar, } \\
\text { jugular }\end{array}$ & GTR \\
\hline 30 & Headaches, CN12 palsy & Hypoglossal schwannoma & $\begin{array}{l}\text { CMC, } \mathrm{HC} / \text { condyle, medial } \\
\mathrm{JF}\end{array}$ & 4Bi & $\begin{array}{l}\text { Modified LDC-RATT + far } \\
\text { lateral }\end{array}$ & $\begin{array}{l}\text { Condylar, } \\
\text { suboccipital, } \\
\text { jugular }\end{array}$ & NTR \\
\hline 31 & $\begin{array}{l}\text { Headaches, NV, CN12 } \\
\text { palsy }\end{array}$ & Hypoglossal schwannoma & $\begin{array}{l}\mathrm{CMC}, \mathrm{JF}, \mathrm{HC} \text {, distal } \\
\text { cervical }\end{array}$ & 4Bt & $\begin{array}{l}\text { Modified LDC-RATT + } \\
\text { retrosigmoid }\end{array}$ & $\begin{array}{l}\text { Carotid, SD, } \\
\text { jugular, mastoid, } \\
\text { condylar }\end{array}$ & STR \\
\hline 32 & $\begin{array}{l}\text { Headaches, neck pain, } \\
\text { CN12 palsy }\end{array}$ & Hypoglossal schwannoma & $\begin{array}{l}\text { CMC, HC/condyle, medial } \\
\text { JF, distal cervical }\end{array}$ & $4 \mathrm{Bt}$ & $\begin{array}{l}\text { Modified LDC-RATT + far } \\
\text { lateral }\end{array}$ & $\begin{array}{l}\text { Carotid, SD, } \\
\text { jugular, condylar }\end{array}$ & GTR \\
\hline
\end{tabular}

TABLE 3: List of lesions treated with a modification of the distal cervical retro-auricular jugular foramen approach by the senior author (JHR).

CMC: cerebello-medullary cistern; CN: cranial nerve; CPA: cerebello-pontine angle; GKS: gamma knife surgery; GTR: gross total resection; HC: hypoglossal canal; IAC: internal auditory canal; JF: jugular foramen; LDC-RATT: lateral distal cervical retroauricular transtemporal approach; NF: neurofibromatosis; NTR: near-total resection (90-99\% resection); NV: nausea/vomiting; SD: stylo-digastric; STR: subtotal resection (<90\%); translab: translabyrinthine.

Type 1A tumors were approached through the carotid triangle. For more distal lesions beyond the angle of the jaw or the digastric muscle (type 1B), the stylodigastric triangle was opened by either mobilizing or detaching the digastric muscle (Figures $2 B, 2 C, 4$, and 8). Intradural tumors (type 2) were mostly located intracranially with limited intraforaminal extension. These were approached through the presigmoid, retrosigmoid, or lateral suboccipital (or far lateral) corridors (Figures $2 A$ and 6). Intraosseous tumors (type 3) were located in the skull base (jugular foramen, occipital condyle, lower part of the mastoid, and petrous bone). These were accessed through the jugular triangle using a classic LDC-RATT approach if the origin of the tumor was believed to be in the jugular foramen (type 3A; Figures $2 d$ and 7 ). Extension along the petrous bone or to the petroclival area (type 3B) dictated a petrosal component to the approach (retrolabyrinthine, translabyrinthine, or a transcochlear approach). A modified LDC-RATT or a far lateral approach with a medially oriented incision, leading to the condylar triangles, was performed whenever the occipital condyle and medial aspect of the jugular foramen were compromised (type 3C; Figures $3 c, 8 a$, and $8 \mathrm{~b}$ ).

Dumbbell-shaped tumors (type 4) required either combined or staged procedures through variations of the retro-auricular approach (Figures $2 b$ and 4). A translabyrinthine, transcochlear, or retrosigmoid part was added to the LDC-RATT approach for type 4Ai tumors to further address the intracranial disease. Stereotactic radiosurgery was helpful to control the foraminal component after either removing the symptomatic intracranial (4Ai) or distal cervical parts (4Ae) in other cases.

True jugular dumbbell-shaped tumors (type 4At, comprising all intracranial, foraminal, and extracranial compartments) were treated with a staged distal cervical followed by retrosigmoid resection, or a combined LDC-RATT and translabyrinthine approach. Type 4B tumors (extending to the condylar triangle) were treated with a modified LDC-RATT approach combined with either a suboccipital retrosigmoid or an intradural far lateral approach (Figures 4 and 8).

In summary, important anatomical factors found to be highly influential on selecting the surgical approach 
included the following: displacement of the distal cervical internal carotid artery (if the tumor moved the artery anteriorly, this dictated a posterolateral, rather than anterior, approach); involvement of the occipital condyle; tumor extension to the petrous bone or to the internal auditory meatus; tumor vascularity and origin of arterial feeders; patency of the sigmoid sinus; and preoperative cranial nerve deficits (described in the Discussion section).

\section{Discussion}

Fisch classified glomus tumors according to their anatomical extension: middle ear (type A), tympanomastoid complex (B), labyrinthine and petrous areas (C), and intracranial (D) [1,2]. GlasscockJackson adopted a similar organization [9]. Fukushima classified jugular foramen schwannomas into intracranial, dumbbell-shaped, and extracranial [3], while he divided hypoglossal schwannomas into intradural, dumbbell-shaped, skull base extracranial, and peripheral tumors (completely extra-cranial) [7]. Similarly, Samii et al. divided jugular foramen schwannomas into intracranial or cisternal tumors (type A); intraosseous tumors (B); extracranial tumors (type $\mathrm{C}$ ); and triple dumbbell-shaped tumors, depending on the employed surgical approach [4].

Given the overlap in surgical approaches and anatomical extensions, we combined previous classifications to help systematize posterolateral skull base and distal cervical lesions, regardless of their pathological diagnosis, in one scheme. Most of these lesions can be simplified into extracranial, intracranial, intraosseous/intraforaminal (at the level of the skull base), and dumbbell-shaped. We believe that this is helpful to tailor the surgical approach and its steps to each lesion and avoid the risks of radical exposures if not necessary.

On the other hand, Fisch divided the post-auricular approach itself into types A, B, and C based on the required anterior exposure. In the classic type A approach, a distal cervical dissection is combined with a radical mastoidectomy, with further transposition of the facial nerve to expose the posterior aspect of the infratemporal fossa and petrous carotid. While the type B approach extends to the petrous apex and clivus, type $\mathrm{C}$ widens the exposure to include the anterior aspect of the middle fossa and infratemporal fossa [17]. The post-auricular approach described by Fisch falls in the lateral group of approaches as classified by Rhoton (post-auricular transtemporal infralabyrinthine approach, and other transmastoid approaches) (Figure 10A) [8]. However, it is more extensive and includes radical steps associated with a higher rate of complications, such as facial nerve transposition. 


\section{Cureus}
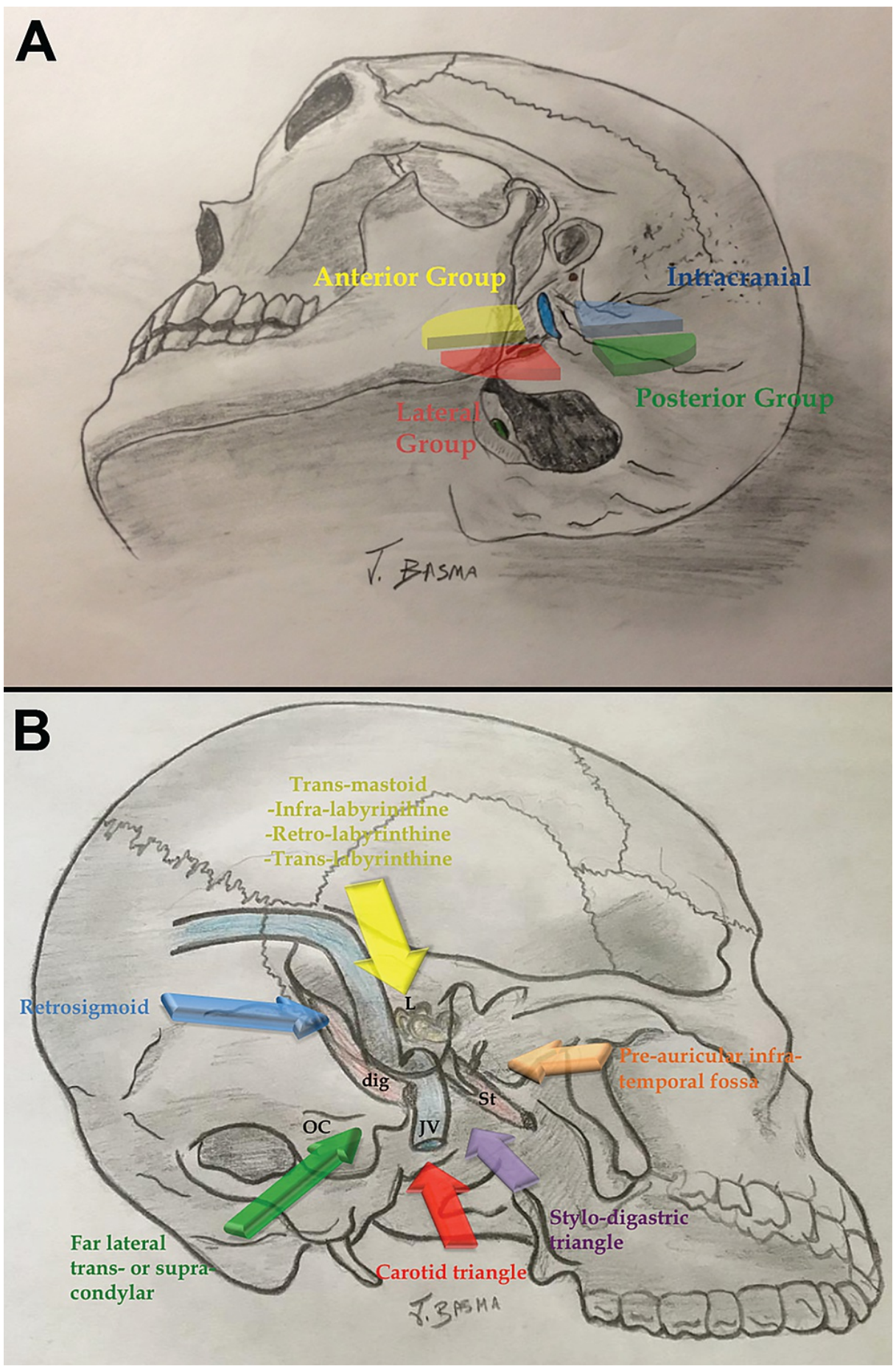

\section{FIGURE 10: Jugular foramen approaches.}

(A) Illustration depicting an adapted classification of jugular foramen approaches by Dr. Albert Rhoton Jr. Intracranial approaches can be performed either through the posterior group (retrosigmoid or far lateral), or lateral group (presigmoid transmastoid approach). (B) Another illustration elucidates the different angles of attack to the jugular foramen as they relate to the lateral distal cervical retro-auricular trans-temporal (LDC-RATT) approach. The lateral cervical dissection includes exposure through the carotid (red) and/or stylodigastric triangles (purple) with the latter overlapping part of-and in many instances supplanting-the anterior pre-auricular infratemporal fossa approach (orange). The transmastoid component of the approach (yellow) provides access to the superior access of the jugular foramen (infralabyrinthine approach). Intracranial exposure can be obtained by combining a presigmoid corridor (retro- and trans-labyrinthine approach) or a retrosigmoid craniotomy (blue). To extend the approach posteromedially, the rectus capitis lateralis can be mobilized and the jugular process drilled (paracondylar exposure). A more medial incision can incorporate a far lateral and trans-condylar (green) component if necessary. Labels: dig: digastric, JV: jugular vein, L: labyrinth, OC: occipital condyle, St: styloid process.

The lateral approach (i.e., LDC-RATT) is versatile and can be customized to the specific anatomical location of the lesion (Figure 10B) [11]. The styloid process may be removed to gain part of the exposure obtained 
from a preauricular subtemporal-infratemporal fossa approach (anterior group) $[8,18]$. The rectus capitis lateralis can be detached and the jugular process of the occipital bone drilled, overlapping with the precondylar variation of the far lateral approach (posterior group) [19]. In a modified LDC-RATT approach, the exposure is combined with a far lateral approach to access the condylar area [20].

To this end, we deconstructed the approach into sequential steps in predictable anatomical triangles (Table 2 and Figure 1). In a similar way with cavernous sinus and middle fossa triangles, these can help compartmentalize the lesion and the operative stages required to reach it. Given the preponderance of radiosurgery and the rarity of these lesions, younger neurosurgeons are becoming less familiar with the subtle nuances of approaching jugular foramen pathologies. Lesions are sometimes deemed inoperable or inaccessible given a poor approach selection. Although not necessary, the triangles can provide young neurosurgeons who are not familiar with the anatomy, with a diagrammatic tool until more intuitive knowledge is developed.

Besides the anatomical relationship with described surgical triangles, several anatomical factors were found to be crucial in deciding the surgical approach. If the internal carotid artery is displaced posteriorly, then an anterior jugular foramen approach needs to be considered, such as opening the stylodigastric triangle and resecting the styloid process (Figures $2 \mathrm{C}$ and 5). However, if the tumor is further anterior in the infratemporal fossa, then a pre-auricular infratemporal fossa approach should be undertaken [18].

Involvement of the occipital condyle and the hypoglossal canal is key in deciding on the medial extent of the approach (Figures 3B, 3C, and 9). In such instances, and even if the tumor originates in the jugular foramen, exposure is carried medially to the transverse process of the atlas in order to allow visualization of the superficial and deep condylar triangles. If the tumor originates more medially toward the foramen magnum, then a more medial approach may be selected (suboccipital or far lateral approach) [14].

Mastoid bone involvement can be divided into two major sectors: infralabyrinthine (or suprajugular) space and a presigmoid sector (retrolabyrinthine, translabyrinthine, and transcochlear approaches) [16]. An infralabyrinthine mastoidectomy usually allows good exposure of the jugular foramen and its superior aspect (Figures $2 \mathrm{~A}$ and 6). If the tumor extends to the petrous bone and petrous ICA, then a petrosal approach should be added to the operative plan [12].

Tumor vascularization should be analyzed in a pre-operative angiographic study. Branches of the ECA (occipital, ascending pharyngeal, posterior auricular, and stylomastoid foramen arteries), can be exposed in the distal carotid and stylodigastric triangles (Figure 4C). Meningeal and muscular branches of the vertebral artery can be exposed in the suboccipital and condylar triangles. Studying venous anatomy is also mandatory. The sigmoid sinus may be already occluded, and it may be possible to ligate and open it (Figures $3 A$ and 7). The insertion of vein of Labbé should be scrutinized to decide the best area in which to perform such a ligation proximally (distal to Labbé) [9]. Venous collaterals may be enlarged and may constitute a major source of bleeding (e.g., vertebral plexus, condylar emissary vein).

Pre-operative cranial nerve deficits can dictate a more aggressive surgical approach, such as a translabyrinthine or transcochlear approach in patients with complete hearing loss (e.g., cases 13,14, and 18); facial nerve transposition in patients with severe facial palsy; more radical resection along the lower cranial nerves in patients with vocal cord paralysis and who already underwent a tracheostomy and/or a gastrostomy tube insertion procedure (e.g., cases 17 and 18). Multidisciplinary postoperative rehabilitation of cranial nerve deficits should be anticipated and started as soon as possible to optimize the chances of long-term recovery.

\section{Conclusions}

Despite their difficulty, lesions located in the distal cervical and postero-lateral skull base (jugular foramen and peri-condylar) regions continue to require surgical interventions in the era of stereotactic radiation. The mainstay of surgical treatment is the selection and implementation of the appropriate approach, providing adequate access without unnecessary, or even risky, dissections. Customizing the approach is simplified using anatomical compartments or triangles, which can be predicted on pre-operative imaging and unlocked in a stepwise fashion. These include the carotid and stylo-digastric triangles in the cervical region, the mastoid triangle, the jugular, condylar and sub-occipital triangles under the digastric muscle, and the deep condylar, supra-hypoglossal, and infra-hypoglossal triangles in the condylar region. The lateral distal cervical retro-auricular trans-mastoid approach is versatile and can be minimized, adjusted, or extended in each case. We provide an anatomical classification and a surgical roadmap to help young neurosurgeons plan these surgeries based on part of the senior author's (Jon H. Robertson) experience.

\section{Additional Information \\ Disclosures}

Human subjects: Consent was obtained or waived by all participants in this study. Institutional Review Board of The University of Tennessee Health Science Center issued approval 20-07874-XP. Institutional 
Review Board approval was provided by The University of Tennessee Health Science Center (No. 20-07874$\mathrm{XP})$. Consent was waived because of the retrospective nature of the data. . Animal subjects: All authors have confirmed that this study did not involve animal subjects or tissue. Conflicts of interest: In compliance with the ICMJE uniform disclosure form, all authors declare the following: Payment/services info: All authors have declared that no financial support was received from any organization for the submitted work. Financial relationships: All authors have declared that they have no financial relationships at present or within the previous three years with any organizations that might have an interest in the submitted work. Other relationships: All authors have declared that there are no other relationships or activities that could appear to have influenced the submitted work.

\section{Acknowledgements}

Andrew J. Gienapp (Neuroscience Institute, Le Bonheur Children's Hospital and Department of Neurosurgery, University of Tennessee Health Science Center, Memphis, TN) provided technical and copy editing; preparation of the manuscript, figures, and tables for publishing; and publication assistance.

\section{References}

1. Oldring D, Fisch U: Glomus tumors of the temporal region: surgical therapy. Am J Otol. 1979, 1:7-18.

2. Fisch U, Mattox D: Microsurgery of the Skull Base. Thieme, Stuttgart-New York; 1988.

3. Jackson CG, Glasscock ME 3rd, Harris PF: Glomus tumors. Diagnosis, classification, and management of large lesions. Arch Otolaryngol. 1982, 108:401-10. 10.1001/archotol.1982.00790550005002

4. Samii M, Alimohamadi M, Gerganov V: Surgical treatment of jugular foramen schwannoma: surgical treatment based on a new classification. Neurosurgery. 2015, 77:424-32; discussion 432. 10.1227/NEU.0000000000000831

5. Bulsara KR, Sameshima T, Friedman AH, Fukushima T: Microsurgical management of 53 jugular foramen schwannomas: lessons learned incorporated into a modified grading system. J Neurosurg. 2008, 109:794803. 10.3171/JNS/2008/109/11/0794

6. Kadri PA, Al-Mefty O: Surgical treatment of dumbbell-shaped jugular foramen schwannomas . Neurosurg Focus. 2004, 17:E9. 10.3171/foc.2004.17.2.9

7. Nonaka Y, Grossi PM, Bulsara KR, Taniguchi RM, Friedman AH, Fukushima T: Microsurgical management of hypoglossal schwannomas over 3 decades: a modified grading scale to guide surgical approach. Neurosurgery. 2011, 69:ons121-40; discussion ons140. 10.1227/NEU.0b013e31822a547b

8. Rhoton AL Jr: Jugular foramen. Neurosurgery. 2000, 47:S267-85. 10.1097/00006123-200009001-00026

9. Michael LM, Hamm W, Robertson JH: Surgical management of intracranial glomus tumors. Neurosurgical Operative Atlas: Neuro-Oncology. 2nd edn. Badie B (ed): Thieme, New York; 2006. 251-259.

10. AANS Neurosurgery: The postauricular transtemporal approach to the jugular foramen [Video] . AANS Neurosurgery YouTube Channel. 2017, https://www.youtube.com/watch?v=ijR1wR4xvrI.

11. Basma J, Michael LM 2nd, Sorenson JM, Robertson JH: Deconstruction of the surgical approach to the jugular foramen region: anatomical study. J Neurol Surg B Skull Base. 2019, 80:518-26. 10.1055/s-00381676512

12. Nelson RA: Temporal Bone Surgical Dissection Manual. House Ear Institute, Los Angeles; 1983.

13. Baron EM, Tunstall R: Back. Gray's Anatomy, The Anatomical Basis of Clinical Practice. 41st edn. Standring S (ed): Elsevier, New York; 2016. 710-50.

14. Heros RC: Lateral suboccipital approach for vertebral and vertebrobasilar artery lesions. J Neurosurg. 1986, 64:559-62. 10.3171/jns.1986.64.4.0559

15. Cohen MA, Evins AI, Lapadula G, Arko L, Stieg PE, Bernardo A: The rectus capitis lateralis and the condylar triangle: important landmarks in posterior and lateral approaches to the jugular foramen. J Neurosurg. 2017, 127:1398-406. 10.3171/2016.9.JNS16723

16. Wanibuchi M, Friedman AH, Fukushima T: Photo Atlas of Skull Base Dissection: Techniques and Operative Approaches. Thieme, New York; 2008.

17. Fisch U: Infratemporal fossa approach to tumours of the temporal bone and base of the skull . J Laryngol Otol. 1978, 92:949-67. 10.1017/s0022215100086382

18. Sekhar LN, Schramm VL Jr, Jones NF: Subtemporal-preauricular infratemporal fossa approach to large lateral and posterior cranial base neoplasms. J Neurosurg. 1987, 67:488-99. 10.3171/jns.1987.67.4.0488

19. Wen HT, Rhoton AL Jr, Katsuta T, de Oliveira E: Microsurgical anatomy of the transcondylar, supracondylar, and paracondylar extensions of the far-lateral approach. J Neurosurg. 1997, 87:555-85. 10.3171/jns.1997.87.4.0555

20. Liu JK, Sameshima T, Gottfried ON, Couldwell WT, Fukushima T: The combined transmastoid retro- and infralabyrinthine transjugular transcondylar transtubercular high cervical approach for resection of glomus jugulare tumors. Neurosurgery. 2006, 59:ONS115-25; discussion ONS115-25.

10.1227/01.NEU.0000220025.81500.8D 